\title{
Exigências líquidas de proteína e energia para ganho de peso de tourinhos Brangus e Nelore alimentados com dietas contendo diferentes proporções de concentrado ${ }^{1}$
}

\author{
Soraia Marques Putrino², Paulo Roberto Leme ${ }^{3}$, Saulo da Luz e Silva ${ }^{2}$, Guilherme Fernando \\ Alleoni $^{4}$, Dante Pazzanese Duarte Lanna ${ }^{5}$, César Gonçalves de Lima ${ }^{6}$, Carlos Grossklaus ${ }^{7}$ \\ ${ }^{1}$ Parte da dissertação de Mestrado da primeira autora apresentada à Faculdade de Zootecnia e Engenharia de Alimentos da Universidade \\ de São Paulo (FZEA/USP). Projeto financiado pela FAPESP. \\ 2 Pós-Graduação - FZEA/USP. Caixa Postal 23, Pirassununga, SP, Brasil - CEP: 13635-900. \\ ${ }^{3}$ Departamento de Zootecnia, FZEA/USP, Pirassununga, SP, Brasil. \\ ${ }^{4}$ Instituto de Zootecnia, Nova Odessa, SP, Brasil. \\ ${ }^{5}$ Departamento de Zootecnia, ESALQ/USP, Piracicaba, SP, Brasil. \\ ${ }^{6}$ Departamento de Ciências Básicas, FZEA/USP, Brasil. \\ 7 Socil Evialis.
}

RESUMO - Foram estimadas as exigências de energia e proteína para ganho de peso de tourinhos das raças Brangus e Nelore, por meio da técnica de abate comparativo, pela estimativa da composição química do corpo vazio a partir do corte da $9^{\mathrm{a}}-10^{\mathrm{a}}-11^{\mathrm{a}}$ costelas. Foram utilizados 28 animais (28 meses de idade) de cada raça, sendo quatro foram abatidos no início do período experimental, para estimativa da composição corporal inicial, e os demais, alimentados sem restrição por 145 dias com dietas contendo 20, 40, 60 ou 80\% de concentrado na matéria seca. Os pesos médios iniciais e finais foram de 238 e $402 \mathrm{~kg}$ para os Brangus e 230,7 e 361,9 kg para os Nelore, respectivamente. Os ganhos diários de peso vivo em jejum, peso de corpo vazio e peso de carcaça quente foram diferentes entre as raças e os níveis de concentrado, com maiores médias para os animais Brangus e para o nível de 60\% de concentrado na dieta. Os animais Brangus apresentaram maiores valores de extrato etéreo e energia e os Nelore, maiores teores de água, proteína e cinzas no corpo vazio. As exigências líquidas de proteína e de energia para o ganho de peso vazio foram diferentes entre raças, com valores de 0,161 e 0,188 kg de proteína e 3,02 e 2,46 Mcal por kg de ganho de peso vazio para os animais Brangus e Nelore, respectivamente. Os animais da raça Brangus tiveram maior exigência de energia e os Nelore, maior exigência de proteína, mas não houve efeito do nível de concentrado na dieta, provavelmente em razão da pouca idade dos animais, que não haviam alcançado a fase de maior deposição de gordura.

Palavras-chave: bovinos de corte, composição corporal, confinamento, crescimento, maturidade

\section{Net energy and protein requirements for weight gain of Brangus and Nellore bulls fed diets containing different concentrate proportions}

\footnotetext{
ABSTRACT - The energy and protein requirements for gain of Brangus and Nellore bulls were estimated using the comparative slaughter technique, in which the empty body as well as the gain composition were estimated through the $9^{\text {th }}-10^{\text {th }}-11^{\text {th }}$ rib cut. Twenty-eight animals from each breed were used in this research. At the beginning of the trial four animals from each breed were slaughtered to determine the initial body composition while the remaining bulls had free access to diets containing 20,40, 60 or $80 \%$ of concentrate (dry matter basis) during 145 days. The average initial and final shrunk body weights were 238 and $402 \mathrm{~kg}$ for Brangus and 230.7 and $361.9 \mathrm{~kg}$ for Nellore, respectively. Animals averaged eight months of age in the beginning of the trial. The final average shrunk body gain, empty body gain, and hot carcass gain differed between breeds and concentrate levels with greater values found for Brangus and $60 \%$ of dietary concentrate, respectively. Fat and energy contents in the empty body were greater for Brangus while water, protein, and ash were higher for Nellore bulls. Protein and energy requirements for empty weight gain differed between breeds averaging 0.161 and $0.188 \mathrm{~kg}$ of protein and 3.02 and 2.46 Mcal of energy per $\mathrm{kg}$ of empty weight gain for Brangus and Nellore, respectively. Although it was observed greater energy requirement for Brangus and greater protein requirement for Nellore, no effect of concentrate level was found probably because the age of the bulls prevented animals to reach a stage of greater fat deposition.
}

Key Words: beef cattle, body composition, feedlot, growth, maturity 


\section{Introdução}

Grande parte do rebanho bovino brasileiro é constituída de animais zebuínos, principalmente da raça Nelore, que, segundo Pineda (2000), apresenta adaptabilidade ao ambiente tropical e adequação ao sistema de produção extensivo. Entretanto, a produtividade destes animais é baixa, principalmente em razão do manejo nutricional deficiente. Cruzamentos entre raças zebuínas e européias são utilizados na tentativa de elevar esta produtividade. Entre estes cruzamentos, a raça Brangus (5/8 Angus e 3/8 Zebu) tem sido amplamente utilizada, porém, suas exigências nutricionais não são bem conhecidas nas condições brasileiras.

A determinação da composição corporal dos animais é fundamental para a avaliação do valor nutricional dos alimentos e para estudos do crescimento animal (Boin et al., 1994), pois possibilita a estimativa das exigências de energia e proteína para o ganho de peso dos animais. Os principais componentes químicos do corpo de um bovino são: água, gordura, proteína e minerais. A maturidade do animal é caracterizada pelo aumento na proporção de gordura. Animais mais jovens têm maior proporção de água e menor de gordura, de modo que as concentrações de proteína, cinzas e água decrescem com a idade e com a engorda (Ferreira et al., 1998).

A proporção e a velocidade com que os tecidos se acumulam no corpo influenciam o ganho de peso vivo, a eficiência alimentar e a composição corporal (Shahin et al., 1993) e, conseqüentemente, as exigências nutricionais.

As proporções dos tecidos e sua composição química são influenciadas por vários fatores, destacando-se o peso, a idade, a raça, o nível de consumo de energia e o sexo (Ferreira et al., 1998). Segundo Garret (1980), a raça teria maior influência sobre a composição corporal, a um mesmo peso vivo, que o nível nutricional.

As diferenças nas exigências de energia e proteína para ganho são atribuídas às variações na composição do ganho depeso (Garret etal., 1959; Geay, 1984). As exigências protéicas para ganho de peso são maiores em animais inteiros nãocastrados de maturidade tardia que nos castrados de maturidade precoce (Geay, 1984). De maneira geral, a maioria dos estudos indica redução nos requerimentos líquidos de proteína à medida que o peso corporal aumenta (Lana et al., 1992; Pires et al.; 1993; Fontes, 1995; Paulino, 1999).

Boin (1995) observou o acréscimo nas exigências de energia líquida para ganho de peso com o aumento do peso vivo e da taxa de ganho de peso em animais Nelore inteiros e castrados e constatou maior concentração de proteína e menor de energia por quilo de ganho de peso do corpo vazio nos animais inteiros.
O NRC (1996) relata que os teores de gordura e proteína corporal apresentam comportamento quadrático em relação ao peso corporal vazio, com relações inversas: quanto maior o peso corporal, maior o teor de gordura e menor o de proteína.

Segundo Geay (1984), os requerimentos líquidos de proteína tendem a ser menos importantes que os de energia para novilhos em crescimento com maturação precoce, como os Angus e Hereford, pois ocorre menor retenção de energia como proteína (12 a 15\%). Esse tipo de animal preenche suas exigências protéicas utilizando somente os aminoácidos provenientes da fermentação microbiana (Geay, 1984).

O objetivo neste trabalho foi estimar as exigências líquidas de proteína e energia para o ganho de peso de tourinhos das raças Brangus e Nelore alimentados com dietas contendo diferentes proporções de concentrado.

\section{Material e Métodos}

O experimento foi realizado na Faculdade de Zootecnia e Engenharia de Alimentos da Universidade de São Paulo (FZEA/USP), em Pirassununga, SP, no segundo semestre de 2000 .

Foram utilizados 56 bovinos machos inteiros Brangus e Nelore (28 animais de cada raça) com idade inicial de oito meses e pesos médios iniciais de 210 e 214 kg, respectivamente. Os animais foram mantidos em pastagem antes do início do confinamento e apresentaram espessura de gordura subcutânea inicial via ultra-som de 0,1 mm para a raça Brangus e 0,2 mm para a raça Nelore (escore corporal próximo a 4, em uma escala de 1 a 9, em que 1 refere-se a animais muito magros e 9, a muito gordos).

Quatro animais de cada raça, escolhidos por sorteio, foram abatidos no início do período de alimentação, para estimativa da composição corporal inicial do lote. Os demais foram confinados, por 145 dias, em quatro piquetes parcialmente cobertos, com 12 animais cada um. A alimentação individual foi controlada por meio de portões eletrônicos do tipo Calan. Antes do início do experimento, todos os animais receberam dieta contendo $20 \%$ de concentrado durante duas semanas, período em que se adaptaram aos portões eletrônicos. Em seguida, os 48 animais confinados passaram por um período de adaptação (28 dias), em que a quantidade de concentrado foi aumentada gradativamente a cada semana até alcançar $80 \%$.

As rações experimentais (Tabela 1 ) foram compostas de silagem de milho (com partículas de aproximadamente $2 \mathrm{~cm}$ e cerca de $35 \%$ de grãos) e 20 , 40, 60 ou $80 \%$ de concentrado 
na matéria seca total. O milho grão foi moído em peneira grossa (8 mm de diâmetro), em forma de quirera. As dietas foram formuladas utilizando-se o programa RLM ${ }^{\circledR}$ (ESALQ/ USP) e fornecidas à vontade aos animais. O alimento, fornecido à vontade, e as sobras foram pesados diariamente, para determinação do teor de matéria seca. O ajuste do fornecimento diário foi feito de forma que as sobras representassem cerca de $10 \%$ do total oferecido. As pesagens dos animais e as medidas de ultra-som foram realizadas em intervalos de 28 dias após jejum completo de 18 horas.

Em cada período (28 dias), foram coletadas amostras da silagem e dos concentrados para análise bromatológica. As amostras de silagem foram secas em estufa de circulação forçada $\left(60^{\circ} \mathrm{C}\right.$, durante 48 horas). As amostras secas da silagem e dos concentrados foram moídas em peneira de $2 \mathrm{~mm}$, retirando-se uma subamostra para análise dos teores de MS, PB, EE e MM (Tabela 2), conforme metodologia de Weende, citado por Silva \& Queiroz (2004). Também foram realizadas as análises de FDN e FDA, segundo procedimentos descritos por Van Soest (1991). Na análise da FDN, não foram extraídos o nitrogênio e as cinzas.

No início do experimento, foi estabelecido valor de 4,5 mm de espessura mínima de gordura subcutânea entre a $12^{\mathrm{a}}$ e $13^{\mathrm{a}}$ costelas para o abate dos animais. Entretanto, como os animais eram muito jovens, seria necessário maior tempo de confinamento, o que não foi possível, em razão das excessivas chuvas no período de verão. Assim, os animais foram abatidos com valor médio de gordura subcu-

Tabela 1 - Composição das rações experimentais (porcentagem da matéria seca)

Table 1 - Composition of the experimental diets (dry matter basis)

\begin{tabular}{|c|c|c|c|c|}
\hline \multirow[t]{2}{*}{$\begin{array}{l}\text { Ingrediente } \\
\text { Ingredient }\end{array}$} & \multicolumn{4}{|c|}{$\begin{array}{c}\text { Porcentagem de concentrado } \\
\text { na dieta (base seca) } \\
\text { Percentage of concentrate in the diet (dry basis) }\end{array}$} \\
\hline & 20 & 40 & 60 & 80 \\
\hline $\begin{array}{l}\text { Silagem de milho } \\
\text { Corn silage }\end{array}$ & 80,00 & 60,00 & 40,00 & 20,00 \\
\hline $\begin{array}{l}\text { Farelo de soja (49\%) } \\
\text { Soybean meal }\end{array}$ & 10,050 & 8,699 & 7,979 & 7,716 \\
\hline $\begin{array}{l}\text { Milho grão seco moído } \\
\text { Ground dry corn grain }\end{array}$ & 6,952 & 27,910 & 48,101 & 67,977 \\
\hline $\begin{array}{l}\text { Uréia } \\
\text { Urea }\end{array}$ & 0,099 & 0,520 & 0,820 & 1,000 \\
\hline $\begin{array}{l}\text { Sulfato de amônio } \\
\text { Ammonium sulfate }\end{array}$ & 0,400 & 0,400 & 0,400 & 0,607 \\
\hline $\begin{array}{l}\text { Cloreto de potássio } \\
\text { Potassium cloride }\end{array}$ & 0,900 & 0,900 & 0,900 & 0,900 \\
\hline $\begin{array}{l}\text { Sal mineralizado } \\
\text { Mineral salt }\end{array}$ & 0,600 & 0,600 & 0,600 & 0,600 \\
\hline $\begin{array}{l}\text { Calcáreo } \\
\text { Limestone }\end{array}$ & 1,000 & 1,000 & 1,200 & 1,200 \\
\hline $\begin{array}{l}\text { Ionóforo } \\
\text { (monensina sódica) } \\
\text { Ionophore (sodic monensin) }\end{array}$ & 0,027 & 0,027 & 0,027 & 0,027 \\
\hline
\end{tabular}

tânea, estimado por ultra-som, de 4 e 3,4 mm para as raças Brangus e Nelore, respectivamente.

O abate dos animais foi realizado dois dias após a última pesagem, após jejum alimentar de 18 horas. Os animais da raça Nelore foram abatidos no Matadouro-Escola da Prefeitura do Campus Administrativo da USP, Pirassununga/SP, e os da raça Brangus, no Frigorífico Minerva, em Barretos/SP.

A partir do peso da carcaça quente (PCQ), obtido pósabate, foi estimado o peso corporal vazio (PCVz), segundo equações de Alleoni et al. (2001), para as raças Brangus (PCVz =12,47625+1,48221 XPCQ; $\mathrm{R}^{2}=$ 0,986; Sxy = 12,569) e Nelore $\left(\mathrm{PCVz}=15,58582+1,45488 \mathrm{X}\right.$ PCQ; $\mathrm{R}^{2}=0,976 ;$ Sxy = 16,261 $)$.

Após o resfriamento das carcaças a $2{ }^{\circ} \mathrm{C}$ por 24 horas, foi retirado o corte da $9^{\mathrm{a}}-10^{\mathrm{a}}-11^{\mathrm{a}}$ costelas da meia-carcaça esquerda, de acordo com metodologia proposta por Hankins \& Howe (1946) e, na área seccionada (entre a 11a e $12^{\mathrm{a}}$ costelas), realizou-se a medida da espessura de gordura subcutânea, utilizando-se grade graduada.

As amostras foram congeladas, cortadas com serra elétrica de fita e processadas em moedor de grande porte (Herman P - 33a - 3 - 789, 15 HP). Em seguida, foram liofilizadas até atingirem peso constante, obtendo-se o teor de água do corte. As amostras liofilizadas foram moídas com gelo seco em liquidificador com copo de aço inox e analisadas quanto aos teores de matéria seca (a $105^{\circ} \mathrm{C}$ ) e extrato etéreo, conforme metodologia de Weende, citado por Silva \& Queiroz (2004).

Considerando o teor de água do corte da $9^{\mathrm{a}}-10^{\mathrm{a}}-11^{\mathrm{a}}$ costelas, foram estimadas as porcentagens de água e gordura no corpo vazio $(\mathrm{CVz})$ dos animais da raça Brangus (*), utilizando-se equações de Alleoni et al. (2003) e Alleoni et al. (2001), respectivamente:

$$
\begin{gathered}
\text { \% água } C V z=0,1413+1,0255 \text { x \% água } 9^{\mathrm{a}}-10^{\mathrm{a}}-11^{\mathrm{a}} \\
\text { costelas; }\left(\mathrm{R}^{2}=0,946 ; \mathrm{Sxy}=0,734\right)
\end{gathered}
$$

\% gordura $C V z=90,14538-1,21282 \times$ \% água $9^{\mathrm{a}}-10^{\mathrm{a}}-11^{\mathrm{a}}$ costelas; $\left(\mathrm{R}^{2}=0,853 ;\right.$ Sxy $\left.=1,08\right)$

Para a raça Nelore $(* *)$, as porcentagens de água e gordura no $\mathrm{CVz}$ foram estimadas a partir da porcentagem de gordura do corte da $9^{\mathrm{a}}-10^{\mathrm{a}}-11^{\mathrm{a}}$ costelas, utilizando-se equações descritas por Lanna (1988):

$$
\text { \% água } C V z=24,1936+0,6574 \times \text { \% água } 9^{\mathrm{a}}-10^{\mathrm{a}}-11^{\mathrm{a}}
$$
costelas; $\left(\mathrm{R}^{2}=0,93 ; \mathrm{Sxy}=6,83\right)$

\% gordura $C V z=8,9+0,0161 \times\left(\%\right.$ gordura $9^{\mathrm{a}}-10^{\mathrm{a}}-11^{\mathrm{a}}$ costelas $)^{2} ;\left(\mathrm{R}^{2}=0,95 ;\right.$ Sxy $\left.=0,82\right)$

Para estimativa dos teores de proteína e cinzas no corpo vazio, foram utilizadas as relações proteína:água $(0,2806)$ e cinzas:água $(0,0649)$, calculadas para tourinhos Brangus por Alleoni et al. (2001), e as relações proteína:água $(0,3077)$ e cinzas:água $(0,0739)$, calculadas para tourinhos Nelore a partir dos dados descritos por Lanna (1988). 
Tabela 2 - Composição química das rações experimentais e dos ingredientes (porcentagem da matéria seca) Table 2 - Chemical ana ingredient composition (\%) of the experimental diets (dry matter basis)

\begin{tabular}{|c|c|c|c|c|c|c|c|}
\hline $\begin{array}{l}\text { Dieta } \\
\text { Diet }\end{array}$ & & $\begin{array}{c}\mathrm{MS}^{1} \\
D M\end{array}$ & & $\begin{array}{l}\mathrm{PB} \\
C P\end{array}$ & $\begin{array}{l}\mathrm{EE} \\
E E\end{array}$ & $\begin{array}{c}\mathrm{MM} \\
M M\end{array}$ & $\begin{array}{l}\mathrm{NDT} \\
\text { TDN }\end{array}$ \\
\hline $\begin{array}{l}\text { Com } 20 \% \text { concentrado } \\
\text { With } 20 \% \text { of concentrate }\end{array}$ & & 41,72 & & 14,37 & 2,53 & 6,34 & 61,43 \\
\hline $\begin{array}{l}\text { Com } 40 \% \text { concentrado } \\
\text { With } 40 \% \text { of concentrate }\end{array}$ & & 53,47 & & 15,33 & 3,03 & 5,48 & 64,10 \\
\hline $\begin{array}{l}\text { Com } 60 \% \text { concentrado } \\
\text { With } 60 \% \text { of concentrate }\end{array}$ & & 65,31 & & 16,20 & 3,39 & 5,99 & 67,05 \\
\hline $\begin{array}{l}\text { Com } 80 \% \text { concentrado } \\
\text { With } 80 \% \text { of concentrate } \\
\text { Ingredientes das dietas } \\
\text { Ingredients of diets }\end{array}$ & & 76,83 & & 17,66 & 3,88 & 4,68 & 73,04 \\
\hline $\begin{array}{l}\text { Ingrediente } \\
\text { Ingredient }\end{array}$ & $\begin{array}{c}\mathrm{MS}^{2} \\
D M\end{array}$ & & $\begin{array}{l}\mathrm{PB} \\
C P\end{array}$ & EE & $\mathrm{MM}$ & $\begin{array}{l}\text { FDN } \\
N D F\end{array}$ & $\begin{array}{l}\text { FDA } \\
A D F\end{array}$ \\
\hline $\begin{array}{l}\text { Silagem de milho } \\
\text { Corn silage }\end{array}$ & 30,86 & & 7,83 & 2,40 & 4,37 & 59,12 & 34,36 \\
\hline $\begin{array}{l}\text { Farelo de soja } \\
\text { Soybean meal }\end{array}$ & 87,81 & & 49,22 & 1,67 & 7,08 & - & - \\
\hline $\begin{array}{l}\text { Milho em grão } \\
\text { Corn grain }\end{array}$ & 89,34 & & 11,51 & 5,46 & 2,27 & - & - \\
\hline
\end{tabular}

${ }^{1}$ Matéria seca total (Total dry matter); ${ }^{2}$ Matéria seca $\left(60^{\circ} \mathrm{C}\right)$ (Dry matter $60^{\circ} \mathrm{C}$ ).

As equações adotadas para o cálculo da composição do corpo vazio não foram validadas, mas os dados dos animais utilizados por Alleoni et al. $(2001,2003)$ e Lanna (1988) são descritos abaixo:

Raça Brangus: as informações referentes aos animais foram descritas por Alleoni et al. (2002). O peso e a idade inicial foram de $324 \mathrm{~kg}$ e 14 meses e o peso no momento do abate, de $510 \mathrm{~kg}$. Os animais avaliados neste experimento possuíam idade (oito meses) e peso (inicial: $238 \mathrm{~kg}$ e final: $402 \mathrm{~kg}$ ) inferiores aos citados anteriormente, mas as equações utilizadas eram as únicas disponíveis para essa raça. Portanto, os dados de exigências para a raça Brangus obtidos neste experimento podem ter algum erro, em decorrência do uso de equações de estimativa da composição corporal desenvolvidas a partir de animais com pesos diferentes.

Raça Nelore: as informações referentes aos animais foram citadas por Lanna (1988). O peso variou entre 180,5 e $496 \mathrm{~kg}$, a idade entre 10 e 30 meses e a gordura no corte da $9^{\mathrm{a}}-10^{\mathrm{a}}-11^{\mathrm{a}}$ costelas entre 11,40 e $27,63 \%$. Neste experimento, os animais Nelore apresentaram idade inicial inferior, mas os pesos inicial e final mantiveram-se na faixa descrita por Lanna (1988). Além disso, os valores da porcentagem de gordura no corte da $9^{\mathrm{a}}-10^{\mathrm{a}}-11^{\mathrm{a}}$ costelas, que variaram de 15,51 a 26,52\%, também estavam no intervalo citado pelo autor.

As quantidades de energia e proteína retidas no ganho de peso vazio foram calculadas a partir da composição corporal dos animais estimada no início e no final do confinamento. O cálculo da energia retida (ER) foi realizado considerando-se valores de 9,442 kcal/g para o extrato etéreo e 5,493 kcal/g para a proteína (Reid et al., 1968; Garret \& Hinman, 1969, citados pelo ARC, 1980).

O rendimento de carcaça (RC) foi calculado pela equação:

$$
\begin{gathered}
\mathrm{RC}=(((\mathrm{PCQ} \text { final }-\mathrm{PCQ} \text { inicial }) /(\text { PVJfinal }- \\
\text { PVJinicial })) * 100)
\end{gathered}
$$

em que PCQ: peso carcaça quente; PVJ: peso vivo em jejum.

Odelineamento experimental foi inteiramente casualizado, em arranjo fatorial $2 \times 4$, com seis repetições. As análises estatísticas foram realizadas utilizando-se o programa SAS (1999), pelo procedimento GLM. A análise de regressão foi feita para as variáveis que apresentaram diferença significativa a 1 ou 5\% entre os níveis de concentrado na dieta.

\section{Resultados e Discussão}

Os valores referentes aos pesos dos animais são apresentados na Tabela 3.

Houve diferença $(\mathrm{P}<0,05)$ entre raças (maiores valores para o Brangus) e níveis de concentrado para os pesos finais, os ganhos de peso vivo em jejum, peso vazio e peso de carcaça quente. Como não houve interação porcentagem de concentrado na dieta $\times$ raças, não foi possível avaliar os ganhos de cada raça, independentemente de cada nível de concentrado na dieta.

As equações de regressão referentes a cada um dos parâmetros que apresentaram diferenças significativas para dietas, de acordo com os níveis de concentrado, para as duas raças, são descritas na Tabela 4. 
Tabela 3 - Peso vivo em jejum (PVJ), peso vazio (PVz), peso de carcaça quente (PCQ), ganhos de peso e rendimento de ganho de tourinhos Brangus e Nelore

Table 3 - $\quad$ Live shrunk weight (LSW), empty body weight (EBW), hot carcass weight (HCW), weight gain and gain efficiency of Brangus and Nellore bulls

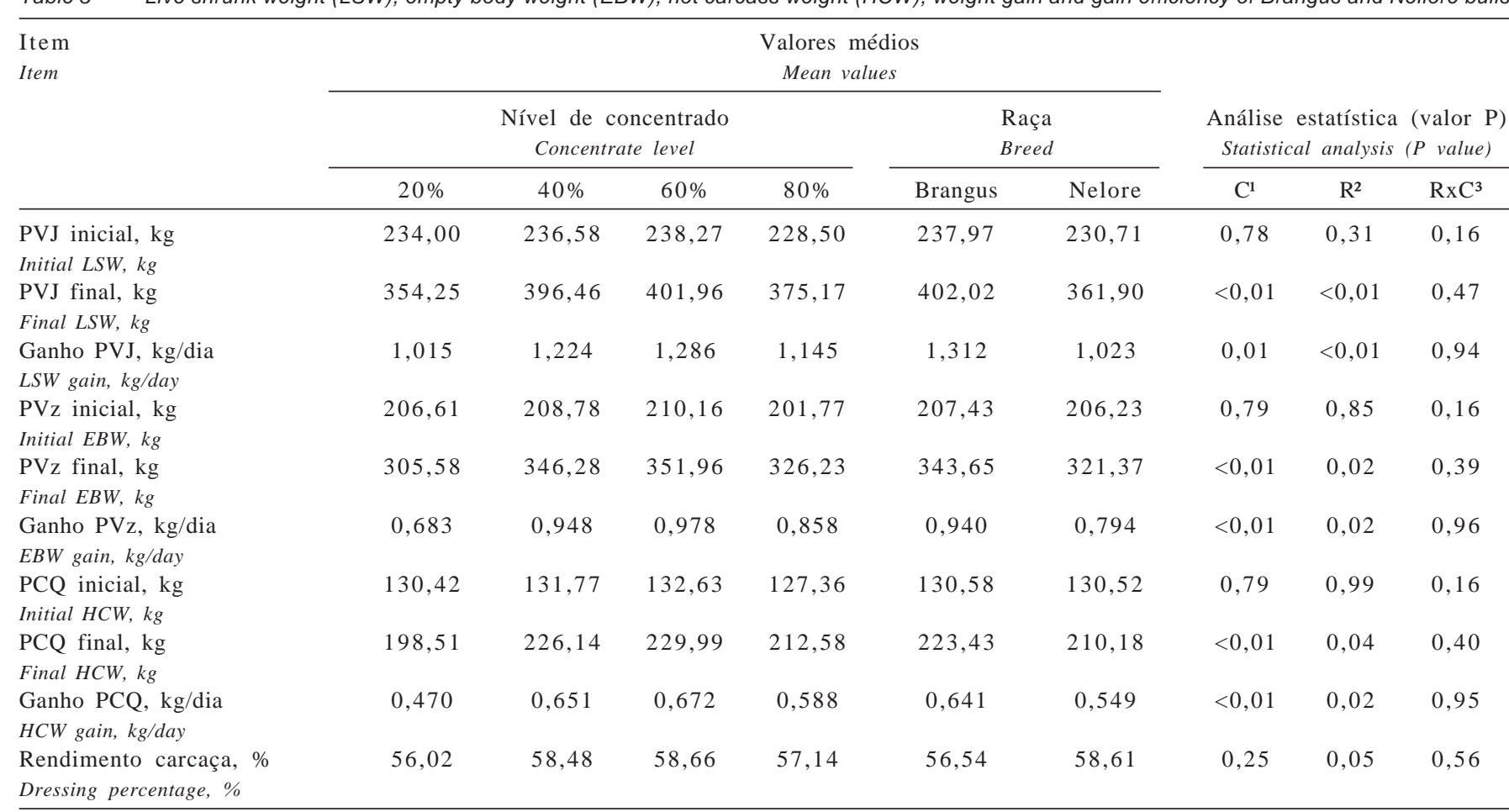

${ }^{1}$ Nível descritivo do teste $\mathrm{F}$ para o fator níveis de concentrado na dieta (C) (p-value for concentrate levels in the diet).

2 Nível descritivo do teste $F$ para o fator raça $(R)$ ( $p$-value for breed effect).

${ }^{3}$ Nível descritivo do teste $\mathrm{F}$ para a interação raça x nível de concentrado (RxC) ( $p$-value for the interaction between breed and concentrate level)

A análise de regressão comprovou efeito quadrático $(\mathrm{P}<0,01)$ para os parâmetros avaliados. Na Figura 1 são demonstrados os ganhos médios de peso vivo em jejum, peso vazio e peso de carcaça quente, de acordo com o nível de concentrado na dieta para ambas as raças.

O fornecimento de $60 \%$, seguido pelo de $40 \%$ de concentrado na dieta de animais Brangus e Nelore, proporcionou maiores ganhos de peso vivo em jejum, peso corporal vazio e peso de carcaça quente. Na Figura 1, consta o efeito quadrático dos tratamentos, observando-se aumento dos ganhos de peso até o nível de $60 \%$ de concentrado na dieta, com redução no tratamento com $80 \%$ de concentrado.

Na Figura 2 são descritos os ganhos de peso de carcaça quente, de acordo com os ganhos de peso vivo em jejum, constatando-se que, apesar de os animais da raça Nelore terem ganhado menos peso que os da raça Brangus (Tabela 3), maior porcentagem deste ganho foi depositada como carcaça, o que é interessante do ponto de vista produtivo. Estes resultados acompanham os dados obtidos para rendimento de carcaça, que foi maior $(\mathrm{P}=0,05)$ para a raça Nelore $(58,61 \%$ vs 56,54\% para a raça Brangus).

Os resultados da composição química do corpo vazio encontram-se na Tabela 5 e os das taxas de deposição dos nutrientes e da composição do ganho de peso vazio, na Tabela 6.

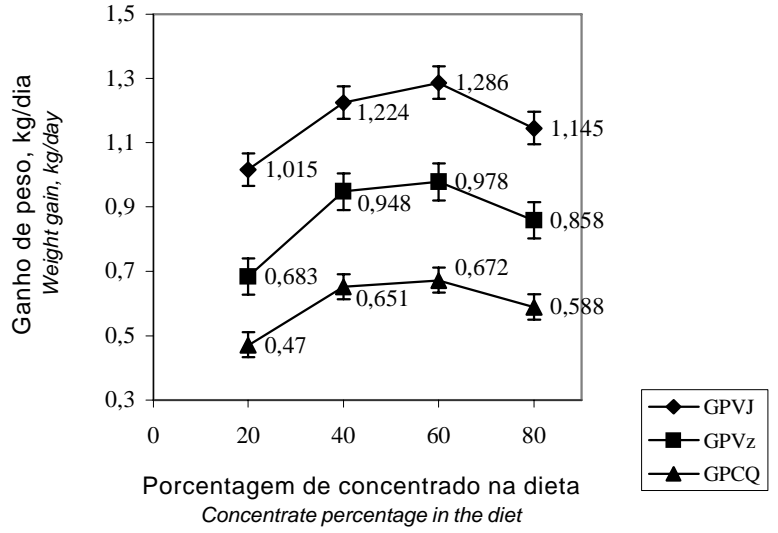

Figura 1 - Ganhos de peso vivo em jejum (GPVJ), peso vazio (GPVz) e peso de carcaça quente (GPCQ) de tourinhos Brangus e Nelore, conforme os níveis de concentrado na dieta.

Figure 1 - Shrunk (SBWG), empty (EBWG) and hot carcass (HCWG) weight gain for Brangus and Nellore bulls according to the dietary concentrate levels.

A composição do corpo vazio não foi alterada pelos níveis de inclusão de concentrado na dieta, mas foi influenciada pelas raças. Os animais da raça Brangus apresentaram maior $(\mathrm{P}<0,01)$ porcentagem de extrato etéreo e, conseqüentemente, maior $(\mathrm{P}<0,01)$ teor de energia $(\mathrm{Mcal} / \mathrm{kg})$ no corpo vazio, enquanto os da raça Nelore tiveram maior $(\mathrm{P}<0,01)$ porcentagem de água, proteína e cinzas no corpo 


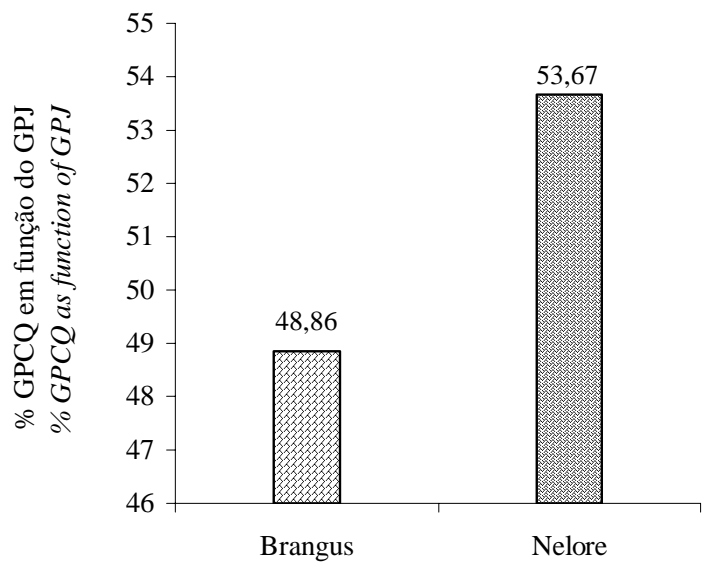

Figura 2 - Ganho de peso de carcaça quente (GPCQ), em porcentagem do ganho de peso vivo em jejum (GPVJ), de tourinhos Brangus e Nelore.

Figure 2 - Hot carcass weight gain (HCWG) as percentage of shrunk weight gain (SWG) of Brangus and Nellore bulls. vazio. Não houve interação dos níveis de concentrado $x$ raças para todos os constituintes corporais avaliados.

As taxas de deposição dos nutrientes foram diferentes $(\mathrm{P}<0,01)$ entre os níveis de concentrado. A análise de regressão indicou efeito quadrático $(\mathrm{P}<0,01)$ para estes parâmetros e as equações obtidas estão descritas na Tabela 7. Como citado anteriormente, não houve interação níveis de concentrado $\times$ raças e, portanto, as equações referem-se às duas raças, conjuntamente.

As maiores taxas de deposição verificadas nos animais alimentados com $60 \%$ de concentrado podem ser confirmadas pelo ganho de peso, que foi maior para este mesmo nível de inclusão. Entre as raças, a Brangus apresentou maior $(\mathrm{P}<0,05)$ taxa de deposição de água, EE e energia, refletida também nos maiores $(\mathrm{P}<0,05)$ ganhos de peso vivo em jejum, peso corporal vazio e peso de carcaça dos animais da raça Brangus em relação aos Nelore.

Tabela 4 - Equações de regressão dos pesos para tourinhos Brangus e Nelore, conforme o nível de concentrado na dieta Table 4 - Regression equations for weight of Brangus and Nellore bulls according to the dietary concentrate level

\begin{tabular}{|c|c|c|}
\hline $\begin{array}{l}\text { Item } \\
\text { Item }\end{array}$ & $\begin{array}{l}\text { Equação de regressão } \\
\text { Regression equation }\end{array}$ & $\mathrm{R}^{2}$ \\
\hline Peso vivo jejum final (kg) (Final shrunk body weight) & $\hat{Y}=-0,0431 X^{2}+4,6538 X+278,65$ & 0,999 \\
\hline Peso vazio final (kg) (Final empty body weight) & $\hat{Y}=-0,0415 X^{2}+4,4898 X+232,57$ & 0,999 \\
\hline Ganho peso vazio (kg/dia) (Shrunk weigth gain, $\mathrm{kg} /$ day) & $\hat{Y}=-0,0002 X^{2}+0,0268 X+0,2468$ & 0,993 \\
\hline Peso carcaça quente final (kg) (Final hot carcass weight) & $\hat{Y}=-0,0282 X^{2}+3,0453 X+148,99$ & 0,999 \\
\hline Ganho peso carcaça quente ( $\mathrm{kg} / \mathrm{dia})$ (Hot carcass weight gain, $\mathrm{kg} /$ day) & $\hat{Y}=-0,0002 X^{2}+0,0184 X+0,1703$ & 0,994 \\
\hline
\end{tabular}

${ }^{1}$ Os valores de $X$ (níveis de concentrado) para as equações de regressão estão em porcentagem (20, 40, 60 ou 80).

${ }^{1}$ The $X$ values (concentrate levels) expressed in percentage $(20,40,60$ or 80$)$

2 Coeficiente de determinação (coefficient of determination).

Tabela 5 - Composição do corpo vazio de tourinhos Brangus e Nelore alimentados com diferentes níveis de concentrado na dieta Table 5 - $\quad$ Empty body composition of Brangus and Nellore bulls fed diets with different concentrate levels

\begin{tabular}{|c|c|c|c|c|c|c|c|c|c|}
\hline \multirow[t]{3}{*}{$\begin{array}{l}\text { Item } \\
\text { Item }\end{array}$} & \multicolumn{6}{|c|}{$\begin{array}{l}\text { Valores médios } \\
\text { Mean values }\end{array}$} & \multirow{2}{*}{\multicolumn{3}{|c|}{$\begin{array}{l}\text { Análise estatística (valor } \mathrm{P} \\
\text { Statistical analysis ( } P \text { value) }\end{array}$}} \\
\hline & \multicolumn{4}{|c|}{$\begin{array}{c}\text { Nível de concentrado } \\
\text { Concentrate level }\end{array}$} & \multicolumn{2}{|c|}{$\begin{array}{l}\text { Raça } \\
\text { Breed }\end{array}$} & & & \\
\hline & $20 \%$ & $40 \%$ & $60 \%$ & $80 \%$ & Brangus & Nelore & $\mathrm{C}^{1}$ & $\mathrm{R}^{2}$ & $\mathrm{RxC}^{3}$ \\
\hline $\begin{array}{l}\% \text { água } \\
\text { Water, \% }\end{array}$ & 60,04 & 59,52 & 58,31 & 59,02 & 57,22 & 61,22 & 0,23 & $<0,01$ & 0,22 \\
\hline $\begin{array}{l}\% \text { proteína } \\
\text { Protein, \% }\end{array}$ & 17,68 & 17,52 & 17,19 & 17,39 & 16,06 & 18,84 & 0,26 & $<0,01$ & 0,24 \\
\hline $\begin{array}{l}\% \text { cinzas } \\
\text { Ash, \% }\end{array}$ & 4,17 & 4,14 & 4,06 & 4,11 & 3,71 & 4,53 & 0,27 & $<0,01$ & 0,26 \\
\hline $\begin{array}{l}\text { Energia (Mcal } / \mathrm{kg}) 2,00 \\
\text { Energy (Mcal } / \mathrm{kg})\end{array}$ & 2,73 & 2,82 & 2,74 & 3,02 & 2,46 & 0,34 & $<0,01$ & 0,10 & \\
\hline
\end{tabular}

${ }^{1}$ Nível descritivo do teste $\mathrm{F}$ para o fator níveis de concentrado na dieta (C) (p-value for concentrate levels in the diet).

2 Nível descritivo do teste $F$ para o fator raça $(R)$ ( $p$-value for breed effect).

3 Nível descritivo do teste F para a interação raça $\times$ nível de concentrado $(\mathrm{R} \times \mathrm{C})(p$-value for the breed $\times$ concentrate level interaction). 
Tabela 6 - Taxas de deposição dos componentes químicos corporais e composição do ganho de peso vazio de tourinhos Brangus e Nelore alimentados com diferentes níveis de concentrado na dieta

Table 6 - Deposition rates of chemical body components and empty weight gain composition of Brangus and Nellore bulls fed diets with different concentrate levels

\begin{tabular}{|c|c|c|c|c|c|c|c|c|c|}
\hline \multirow[t]{3}{*}{$\begin{array}{l}\text { Item } \\
\text { Item }\end{array}$} & \multicolumn{6}{|c|}{$\begin{array}{l}\text { Valores médios } \\
\text { Mean values }\end{array}$} & & & \\
\hline & \multicolumn{4}{|c|}{$\begin{array}{l}\text { Nível de concentrado } \\
\text { Concentrate level }\end{array}$} & \multicolumn{2}{|c|}{$\begin{array}{l}\text { Raça } \\
\text { Breed }\end{array}$} & \multicolumn{3}{|c|}{$\begin{array}{l}\text { Análise estatística (valor } \mathrm{P} \\
\text { Statistical analysis ( } P \text { value) }\end{array}$} \\
\hline & $20 \%$ & $40 \%$ & $60 \%$ & $80 \%$ & Brangus & Nelore & $\mathrm{C}^{1}$ & $\mathrm{R}^{2}$ & $\begin{array}{l}\mathrm{R} \times \mathrm{C}^{3} \\
B \times C\end{array}$ \\
\hline \multicolumn{10}{|l|}{$\begin{array}{l}\text { Taxas de deposição } \\
\text { Deposition rates }\end{array}$} \\
\hline $\begin{array}{l}\text { Água, kg/dia } \\
\text { Water, kg/day }\end{array}$ & 0,415 & 0,526 & 0,560 & 0,540 & 0,536 & 0,484 & $<0,01$ & 0,02 & 0,51 \\
\hline $\begin{array}{l}\text { Extrato etéreo, } \mathrm{kg} / \mathrm{dia} \\
\text { Ether extract, } \mathrm{kg} / \text { day }\end{array}$ & 0,128 & 0,169 & 0,198 & 0,176 & 0,215 & 0,120 & $<0,01$ & $<0,01$ & 0,11 \\
\hline $\begin{array}{l}\text { Proteína, kg/dia } \\
\text { Protein, } \mathrm{kg} / \text { day }\end{array}$ & 0,122 & 0,154 & 0,164 & 0,159 & 0,151 & 0,149 & $<0,01$ & 0,79 & 0,53 \\
\hline $\begin{array}{l}\text { Cinzas, kg/dia } \\
\text { Ash, kg/day }\end{array}$ & 0,029 & 0,036 & 0,039 & 0,037 & 0,035 & 0,036 & $<0,01$ & 0,55 & 0,54 \\
\hline $\begin{array}{l}\text { Energia, Mcal/dia } \\
\text { Energy, Mcal/day }\end{array}$ & 1,88 & 2,44 & 2,77 & 2,53 & 2,86 & 1,95 & $<0,01$ & $<0,01$ & 0,23 \\
\hline \multicolumn{10}{|c|}{$\begin{array}{l}\text { Composição do ganho de peso vazio (GPVz) } \\
\text { Empty weight gain (EWG) composition }\end{array}$} \\
\hline $\begin{array}{l}\text { \% Água } \\
\text { Water, \% }\end{array}$ & 60,16 & 59,56 & 58,66 & 59,37 & 57,42 & 61,45 & 0,29 & $<0,01$ & 0,13 \\
\hline $\begin{array}{l}\% \text { Extrato etéreo } \\
\text { Ether extract, \% }\end{array}$ & 17,94 & 18,77 & 19,97 & 19,01 & 22,74 & 15,10 & 0,30 & $<0,01$ & 0,13 \\
\hline $\begin{array}{l}\text { \% Proteína } \\
\text { Protein, \% }\end{array}$ & 17,72 & 17,54 & 17,29 & 17,50 & 16,11 & 18,91 & 0,31 & $<0,01$ & 0,13 \\
\hline $\begin{array}{l}\% \text { Cinzas } \\
\text { Ash, } \%\end{array}$ & 4,18 & 4,14 & 4,08 & 4,13 & 3,73 & 4,54 & 0,34 & $<0,01$ & 0,13 \\
\hline \multicolumn{10}{|c|}{$\begin{array}{l}\text { Exigências líquidas para ganho } \\
\text { Net gain requirements }\end{array}$} \\
\hline $\begin{array}{l}\text { Energia, Mcal } / \mathrm{kg} \text { GPVz } \\
\text { Energy, Mcal/kg EWG }\end{array}$ & 2,06 & 2,73 & 2,82 & 2,74 & 3,02 & 2,46 & 0,34 & $<0,01$ & 0,10 \\
\hline $\begin{array}{l}\text { Proteína, kg/kg GPVz } \\
\text { Protein, } \mathrm{kg} / \mathrm{kg} \text { EWG }\end{array}$ & 0,177 & 0,175 & 0,172 & 0,174 & 0,160 & 0,188 & 0,25 & $<0,01$ & 0,24 \\
\hline $\begin{array}{l}\text { Gordura, kg/kg GPVz } \\
\text { Fat, kg/kg EWG }\end{array}$ & 0,179 & 0,188 & 0,198 & 0,189 & 0,226 & 0,150 & 0,33 & $<0,01$ & 0,11 \\
\hline
\end{tabular}

${ }_{1}^{1}$ Nível descritivo do teste $\mathrm{F}$ para o fator níveis de concentrado na dieta (C) (p-value for concentrate levels in the diet).

${ }^{2}$ Nível descritivo do teste $F$ para o fator raça $(R)$ ( $p$-value for breed effect).

${ }^{3}$ Nível descritivo do teste $F$ para a interação raça $\times$ nível de concentrado $(R \times C)(p$-value for the breed $\times$ concentrate level interaction $[B \times C])$.

A composição do ganho de peso corporal vazio diferiu apenas entre as raças. Os animais da raça Brangus apresentaram maior porcentagem de gordura, enquanto os da raça Nelore, maiores porcentagens de água, proteína e cinzas, o que sugere que os animais da raça Brangus são mais precoces quanto à deposição de gordura.

É importante salientar que o peso tem influência sobre a composição corporal, pois a proporção de gordura aumenta juntamente com o peso do animal. Como os animais da raça Brangus apresentaram peso final maior $(\mathrm{P}<0,01)$ que os Nelore, era esperado que a porcentagem de gordura também fosse maior.

Segundo Grant \& Helferich (1991), a causa dessas alterações é a desaceleração do crescimento muscular, confirmada pelo menor ganho de proteína por kg de ganho de peso corporal vazio (GPVz) e pelo aumento na deposição de gordura e do ganho de gordura por kg de GPVz, à medida que o peso corporal aumenta.

A precocidade da raça Brangus em comparação à Nelore também foi observada por Pelicioni et al. (1999), que compararam a idade ao primeiro parto de fêmeas Nelore e F1 de várias raças com Nelore, entre elas a Brangus, e observaram menor idade para os animais cruzados. A menor idade ao primeiro parto foi para os animais cruzados Nelore x Angus, seguidos pelo Nelore $x$ Brangus. Portanto, os animais da raça Brangus atingem mais precocemente a maturidade fisiológica que os Nelore. 
Tabela 7 - Equações de regressão das taxas de deposição dos componentes químicos corporais em tourinhos Brangus e Nelore, conforme o nível de concentrado na dieta

Table 7 - Regression equations for deposition rates of chemical body components of Brangus and Nellore bulls according to the dietary concentrate level

\begin{tabular}{|c|c|c|}
\hline $\begin{array}{l}\text { Item } \\
\text { Item }\end{array}$ & $\begin{array}{l}\text { Equação de regressão }{ }^{1} \\
\text { Regression equation }\end{array}$ & $\mathrm{R}^{2}{ }^{2}$ \\
\hline Água (kg/dia) (Water, kg/day) & $\hat{Y}=-0,8144 X^{2}+1,0189 X+0,2448$ & 0,998 \\
\hline Extrato etéreo (kg/dia) (Ether extract, $\mathrm{kg} /$ day) & $\hat{Y}=-0,3975 X^{2}+0,4837 X+0,045$ & 0,972 \\
\hline Proteína (kg/dia) (Protein, kg/day) & $\hat{Y}=-0,0958 X^{2}+0,1244 X+0,1215$ & 0,991 \\
\hline Cinzas (kg/dia) (Ash, kg/day) & $\hat{Y}=-0,055 X^{2}+0,0691 X+0,0172$ & 0,998 \\
\hline Energia (Mcal/dia) (Energy, kg/day) & $\hat{Y}=-0,0005 X^{2}+0,0619 X+0,8216$ & 0,988 \\
\hline
\end{tabular}

${ }^{1}$ Os valores de $X$ (níveis de concentrado) para as equações de regressão estão em números decimais $(0,20 ; 0,40 ; 0,60$ ou 0,80) a fim de elevar os valores dos coeficientes de $X$.

1 The $X$ values (concentrate levels) are expressed in decimal $(0.2,0.4,0.6$ or 0.8$)$ to raise the values of $X$ coefficient.

2 Coeficiente de determinação (coefficient of determination).

Infere-se que não só o peso, mas também o efeito racial, contribuiu para as diferenças na composição corporal, sobretudo o teor de gordura, entre animais Brangus e Nelore.

Diversos pesquisadores - Veloso et al. (2002), em tourinhos F1 Limousin x Nelore; Ferreira et al. (1998), em bovinos F1 Simental x Nelore não-castrados; Véras et al. (2000), em animais Nelore não-castrados; e Fontes (1995), em revisão de vários trabalhos - também observaram aumento nas concentrações de gordura e energia e diminuição na de proteína com a elevação do peso vivo em jejum.

As exigências de energia (Mcal/kg de GPVz) e proteína ( $\mathrm{kg} / \mathrm{kg}$ de GPVz) foram diferentes apenas entre raças (Tabela 6). A raça Nelore apresentou maiores exigências de proteína e a Brangus, maiores exigências de energia e, conseqüentemente, ganho de gordura em kg/kg de GPVz.

Fontes (1995) registrou, em animais F1 Angus x Nelore e Nelore, exigências líquidas de proteína menores e de ganho de gordura maiores que os dos Brangus e Nelore deste experimento, provavelmente porque os animais utilizados por esses autores foram abatidos com maior peso vivo.

Bulle et al. (2002) não encontraram, em tourinhos mestiços Europeu x Zebu, efeito de raça paterna (britânica ou continental) ou de tratamento ( 79,85 ou $91 \%$ de concentrado na dieta) na composição do ganho de peso corporal vazio. Os animais de raça paterna britânica apresentaram 28,9\% de gordura e 3,67 Mcal/kg de GPVz, maiores que os registrados para os Brangus deste experimento (22,74\% de gordura e 3,02 Mcal).

Tedeschi et al. (2002) realizaram estudo com animais Nelore, inteiros e castrados, recebendo $40 \%$ de concentrado na dieta, com alimentação à vontade ou restrita e, nos animais inteiros, não observaram diferença entre tratamentos para as porcentagens de água (61,9 e 63,2\%) e proteína (18,5 e 18,6\%) no PCVz, respectivamente. Para gordura (56,5 e 48,9\%) e proteína (17,5 e 18,3\%) no GPVz, também não foram constatadas diferenças entre os animais alimentados ad libitum ou com restrição.
Não se observou efeito do nível de concentrado para a composição corporal. A ausência de efeito da alimentação sobre a composição do ganho de peso e sobre as exigências líquidas para o ganho podem ter decorrido da idade jovem dos animais (não haviam alcançado a fase de maior deposição de gordura) ou da inclusão de $80 \%$ de concentrado na dieta, que diminuiu o ganho de peso e as taxas de deposição dos nutrientes.

\section{Conclusões}

Os animais da raça Brangus apresentaram exigências de energia e taxa de deposição de gordura mais elevadas que os da raça Nelore, que, por sua vez, tiveram maiores exigências de proteína.

A porcentagem de concentrado na dieta não alterou a composição do ganho de peso corporal vazio e as exigências líquidas para o ganho de peso, provavelmente em razão da idade jovem dos animais, que ainda não haviam alcançado a fase de maior deposição de gordura.

A inclusão de $80 \%$ de concentrado na dieta parece ter afetado os resultados, pois diminuiu o ganho de peso dos animais e as taxas de deposição dos nutrientes.

\section{Literatura citada}

AGRICULTURAL RESEARCH COUNCIL - ARC. The nutrient requirements of ruminants livestock. London: Commonwealth Agricultural Bureaux, 1980. 351p.

ALLEONI, G.F.; LEME, P.R.; BOIN, C. et al. Evaluation of the chemical and physical composition of rib cuts as predictors of body composition of Canchim and Brangus youn bulls. In: Ix WORLD CONFERENCE ON ANIMAL PRODUCTION, 9., REUNIÃO DA ASSOCIAÇÃO LATIONOAMERICANA DE PRODUÇÃO ANimAL, 17., Porto Alegre. Anais... Porto Alegre: 2003 (CD-Rom).

ALLEONI, G.F.; LEME, P.R.; BOIN, C. et al. Composição química corporal e taxas de deposição dos constituintes químicos do corpo vazio em bovinos das raças Nelore, Canchim e Brangus. In: REUNIÃO ANUAL DA SOCIEDADE BRASILEIRA DE ZOOTECNIA, 34., Recife. Anais... Recife: 2002 (CD-ROM). 
ALLEONI, G.F.; LEME, P.R.; BOIN, C. et al. Determinação da composição do corpo vazio, do ganho de peso, e das exigências de energia e proteína para mantença e ganho de peso em bovinos da raça Nelore, Canchim e Brangus. Nova Odessa: Instituto de Zootecnia de Nova Odessa, 04/2001. Relatório Científico Fapesp: Processo 97/02590-5.

BOIN, C. Alguns dados sobre exigências de energia e de proteína de zebuínos. In: SIMPÓSIO INTERNACIONAL SOBRE EXIGÊNCIAS NUTRICIONAIS DE RUMINANTES, 1995, Viçosa, MG. Anais... Viçosa, MG: Universidade Federal de Viçosa, 1995. p.457-465.

BOIN, C.; LEME, P.R.; LANNA, D.P.D. et al. Tourinhos Nelore em crescimento e acabamento. 2. Exigências de energia líquida de mantença e eficiência de utilização da energia metabolizável para mantença e crescimento. In: REUNIÃO ANUAL DA SOCIEDADE BRASILEIRA DE ZOOTECNIA, 1994, Maringá, Anais... Maringá: Sociedade Brasileira de Zootecnia, 1994. p.473.

BULLE, M.L.M.; RIBEIRO, F.G.; LEME, P.R. et al. Exigências líquidas de energia e proteína de tourinhos de dois grupos genéticos alimentados com dietas de alto teor de concentrado. Revista Brasileira Zootecnia, v.31, n.1, p.436-443, 2002.

FERREIRA, M.A., VALADARES FILHO, S.C.; COELHO da SILVA, J.F. et al. Composição corporal e exigências líquidas de proteína e energia para ganho de peso de bovinos F1 Simental X Nelore - Revista Brasileira Zootecnia, v.28, n.2, p.352-360, 1998.

FONTES, C.A.A. Composição corporal, exigências líquidas de nutrientespara ganho de peso e desempenho produtivo de animais zebuínos e mestiços europeu-zebu. Resultados experimentais. In: SIMPÓSIO INTERNACIONAL SOBRE EXIGÊNCIAS NUTRICIONAIS DE RUMINANTES, 1995, Viçosa, MG. Anais... Viçosa, MG: Universidade Federal de Viçosa, 1995. p.419-455.

FOX, D.G.; SNIFFEN, C.J.; O'CONNOR, J.D. et al. Search: agriculture. Ithaca: Cornell University Agric. Exp. Sta., n.34, 1992. 128p.

GARRET, W.N. Factor influencing energetic efficiency of beef production. Journal of Animal Science, v.51, n.6, p.14341440,1980

GARRET, W.N.; MEYER, J.H.; LOFGREEN, J.P. The comparative energy requirements of sheep and cattle for maintenance and gain. Journal of Animal Science, v.18, n.2, p.528-547, 1959.

GEAY, Y. Energy and protein utilization in growing cattle. Journal of Animal Science, v.58, n.3, p.766-778, 1984.

GRANT, A.L.; HELFERICH, W.G. An overview of growth. In: PEARSON, A.M.; DUTSON, T.R. (Eds.). Growth regulation in farm animals. London: Elsevier Applied Science, 1991. p.1-15.

HANKINS, O.G.; HOWE, P.E. Estimation of the composition of beef carcasses and cuts. Washington, USDA, 1946. (Technical Bulletin, 926).

LANA, R.P.; FONTES, C.A.A.; PERON, A.J. et al. Composição corporal e do ganho de peso e exigências de energia, proteína e macro elementos minerais ( $\mathrm{Ca}, \mathrm{P}, \mathrm{Mg}$, $\mathrm{Na}$ e $\mathrm{K}$ ), de novilhos de cinco grupos raciais. 2. Exigências de energia e proteína. Revista Sociedade Brasileira Zootecnia, v.21, n.3, p.528-537, 1992.
LANNA, D.P.D. Estimativa da composição química do corpo vazio de tourinhos Nelore através da gravidade específica da carcaça e da composição química de cortes das costelas. Piracicaba: Escola Superior de Agricultura Luiz de Queiroz, 1988. 131p. Dissertação (Mestrado em Agronomia) - Escola Superior de Agricultura Luiz de Queiroz, 1988.

NATIONAL RESEARCH COUNCIL - NRC. Nutrients requirements of beef cattle. 7.ed. Washington, D.C.: National Academy Press, 1996. 242p.

PAULINO, M.F.; FONTES, C.A.A.; JORGE, A.M.; GOMES JR., P. Composição corporal e exigências de energia e proteína para ganho de peso de bovinos de quatro raças zebuínas. Revista Brasileira Zootecnia, v.28, n.3, p.627-633, 1999.

PELICIONI, L.C.; MUNIZ, C.A.S.D.; QUEIROZ, S.A. Avaliação do desempenho ao primeiro parto de fêmeas nelore e F1. Revista Brasileira Zootecnia, v.28, n.4, p.729-734, 1999.

PINEDA, N. R. Influência do Nelore na produção de carne no Brasil. In: SIMPÓSIO NELORE 2000, 2000, Ribeirão Preto. Anais... Ribeirão Preto: 2000. p.3-13.

PIRES, C.C.; FONTES, C.A.A.; GALVÃO, J.G. et al. Exigências nutricionais de bovinos de corte em acabamento. I. Composição corporal e exigências de proteínas para ganho de peso. Revista Sociedade Brasileira Zootecnia, v.22, n.1, p.110-120, 1993.

STATISTICAL ANALYSES SYSTEM - SAS. The SAS system for Windows Version 8. 5.ed. Cary: 1999.

SHAHIN, K.A.; BERG, R.T.; PRICE, M.A. The effect of breedtype and castration on tissue growth patterns and carcass composition in cattle. Livestock Production Science, v.35, n.3/4, p.251-264, 1993.

SILVA, D.J.; QUEIROZ, A.C. Análise de alimentos (Métodos químicos e biológicos). 3.ed. Viçosa, MG: Universidade Federal de Viçosa, 2004. 235p.

TEDESCHI, L.O.; BOIN, C.; FOX, D.G. et al. Energy requirement for maintenance and growth of Nelore bulls and steers fed high-forage diets. Journal of Animal Science, v.80, p.16711682, 2002.

Van SOEST, P.J.; ROBERTSON, J.B.; LEWIS, B.A. Methods for dietary fiber, neutral detergent fiber and non-starch polysaccharides in relation to animal nutrition. Journal Dairy Science, v.74, p.3583-3597, 1991.

VELOSO, C.M.; VALADARES FILHO, S.C.; GESUALDI JR., A. et al. Composição corporal e exigências energéticas e protéicas de bovinos F1 Limousin x Nelore, não-castrados, alimentados com rações contendo diferentes níveis de concentrado. Revista Brasileira Zootecnia, v.31, n.3, p.1273-1285, 2002.

VÉRAS, A.S.C. ; VALADARES FILHO, S.C. ; COELHO DA SILVA, J.F. et al. Composição corporal e requisitos energéticos e protéicos de bovinos Nelore, não-castrados, alimentados com rações contendo diferentes níveis de concentrado. Revista Brasileira Zootecnia, v.29, n.6, p.2379-2389, 2000.

Recebido: 20/03/04 Aprovado:22/09/05 